\title{
Towards a Kantian Theory of Judgment: the Power of Judgment in its Practical and Aesthetic Employment
}

\author{
Dascha Düring $^{1} \cdot$ Marcus Düwell $^{1}$
}

Accepted: 29 September 2015 / Published online: 13 October 2015

(C) The Author(s) 2015. This article is published with open access at Springerlink.com

\begin{abstract}
Human beings orient themselves in the world via judgments; factual, moral, prudential, aesthetic, and all kinds of mixed judgments. Particularly for normative orientation in complex and contested contexts of action, it can be challenging to form judgments. This paper explores what one can reasonably expect from a theory of the power of judgment from a Kantian approach to ethics. We reconstruct practical (prudential and moral) judgments on basis of the self-reflexive capacities of human beings, and argue that for the subject to see himself as committed to prudential goods it is necessarily implied that he understands himself as committed to moral judgment. However, to understand the normativity of understanding oneself as a being with practical commitments at all, the aesthetic judgment is introduced: the power of judgment in its pure form of selfreflexivity. We claim that aesthetic reflection and judgment is conditional on the possibility for human beings to enter the space of reasons, and therewith for practical self-understanding as such. The paper concludes with a preliminary sketch of different conceptual possibilities in fleshing out the role of the power of judgment in its aesthetic employment in developing mixed judgments.
\end{abstract}

Keywords Power of judgment · Practical self-understanding - Self-reflexivity · Aesthetics · Morality $\cdot$ Mixed judgments

The capacity to form judgments is the basic power that human beings need in order to orient themselves in the world. The power of judgment allows human beings to understand and position themselves in and relate themselves to the world, other people and themselves. In forming and articulating judgments we are capable to form bridges between our own subjectivity and objects of perception, as well as the latter in relation to each other. There are different forms of judgments: theoretical, prudential, moral, aesthetic, as well as various kinds of mixed

Dascha Düring

d.k.during@uu.nl

Marcus Düwell

m.duwell@uu.nl

1 Department of Philosophy and Religious Studies, University of Utrecht, Janskerkhof 13A, 3511 VK Utrecht, the Netherlands 
judgments. We judge the existence and qualities of objects, our impression of landscapes, the appropriateness and acceptability of human behavior, and in more complex circumstances such singular judgments are combined in one of a mixed nature. Human beings often disagree about their judgments, but at the same time we also understand each other to some degree; we very often agree in judging that the cat is on the mat, in judging murder as unacceptable, and in finding the setting sun beautiful. This is surprising because there seems to be an irreducible level of subjectivity in the capacity of judging.

In the contemporary world it is increasingly difficult to actualize our capacity to judge: our increasing access to knowledge of the complex contextual embedding of societal challenges that urgently require answers makes it challenging to form reflected judgments. For instance questions regarding climate change, the European Union, extremism and terrorism form a challenge for our power of judgment: there is an overabundance of historical-contextual factors as well as multi-level perspectives that need to be taken into account, proper responses to such challenges mostly demand coordinated action of a tremendous variety of actors, and the consequences of different responses are often to a relevant extent uncertain. This makes it complicated to formulate rationally justifiable standpoints that are at the same time sufficiently concrete so as to include and exclude specific normative commitments and perspectives on (collective) action.

But on the more basic level, the requirements of mixed judgments are especially challenging to the judging subject. Judging e.g. how we should respond to climate change demands that individuals develop a normative perspective on how they ought to act that takes all kinds of factors into account: making a reflected judgment about what to do, presupposes that subjects have the capacity to relate normative judgments to what they want and what they know. It presupposes that they take all kinds of facts about ecological challenges into account, divergent judgments by relevant experts, judgments about probabilities of the efficiency of possible measures, judgments about possible side-effects on people in different parts of the world, preferences of various individuals and collective parties involved, and the effects that different strategies will have on the lives of current generations but also that of future ones. And we also have to assume that subjects have the capacity to form moral judgments that can be overriding vis-à-vis prudential considerations, such as those with regard to their own happiness.

To develop a reflected normative judgment on how to act under those complex circumstances requires of subjects that they can form mixed judgments that combine various kinds of singular judgments (about facts, probabilities, preferences, legal and moral norms etc.). An ethics capable of dealing with the complexity of the modern world needs to have an understanding under which preconditions such complex mixed judgments can be formed. There is an abundance of philosophical literature on judgments, as well as empirical research on how people actually form these and which parameters influence the procedure of judging. But in order to understand the conceptual relationships between the varying judgments we need a systematic philosophical analysis of the power of judgment - to understand how the power of judgment in its different employments (theoretical, prudential, moral, aesthetic) could be reconstructed to function.

This paper explores what one can reasonably expect from a theory of the power of judgment from a Kantian approach to ethics. We do not see this as an exegetical but as a systematic endeavor that takes its inspiration from the works of Kant and a variety of contemporary Kantian philosophers (notably Longuenesse 1998; Steigleder 2003; Herman 2007; Waxman 2014; Makkreel 2015). These authors have in common that they emphasize that a Kantian 
perspective will not start philosophical inquiry with concepts and propositions but with judgments - which means that the relationship of the judging subject to those concepts and propositions is conceived as irreducible. Also emphasizing the priority of judgment, the paper relates the moral philosophy of Gewirth (1978) to the Kantian perspective.

The main question of the paper is: what does developing moral judgments in complex circumstances presuppose and how is the capacity to form moral judgments interrelated with other employments of the power to judge? We will claim that the development of mixed judgments presupposes that subjects have the capacity for taking up a reflexive stance towards their own judgments, and that they are able to relate to, place, and order different forms of judgments. That means that they need to be able to adopt a position that allows for a distance from their particular judgments and creates space for self-reflexivity; which enables them to develop a reflected view on how they want, can, and ought to relate these different judgments to each other. Concretely we will argue that prudential judgments ought to be understood as reflexive judgments that presuppose a self-reflexive stance, which is internally related to the moral judgment - which is also reflexive and presupposes a self-reflexive dimension. Thereafter we will focus on the role of self-reflexivity in judgment, and will propose that the functioning of the power of judgment in its aesthetic employment forms a necessary element for the exercise of the power of judgment in general. Ultimately we will attempt to make a preliminary sketch of what would be expected from a Kantian theory of mixed moral judgment in complex circumstances, where we especially focus on the anticipated consequences of giving aesthetic reflection a prominent place in a theory of judgment. Before turning to discuss the power of judgment, we will make some remarks about how we understand the basic methodological starting points of the Kantian project.

\section{Aims and Assumptions: Understanding Understanding}

The paper has its basic starting point in the idea that all knowledge must come in judgments (Kant 1998: A68-69; B93-94), but that the capacity to judge should not primordially be understood to concern what we can know. The former we take to be relatively uncontroversial, the latter deserves elaboration. Prior to the question whether and how we can know something, is the question whether and how we can think something - 'if we cannot think something, the question whether we can know it cannot even arise' (Waxman 2014: 3). Understanding what it means to know something therefore presupposes understanding what it means to understand something, and we approach the power of judgment in the latter light. We thus assume that all understanding comes in judgments, and that the capacity to judge primordially concerns what can be understood. With this, the self-reflexive structure of the power of judgment becomes apparent: understanding what it means to judge implies an understanding of understanding. This of course does not mean that the subject can only claim to understand his own judgments if these are thought against the background of an elaborate account of the limits of possible understanding - although one can question whether a total lack of self-reflexivity in judgment makes it even possible to conceive such a subject as a judging subject. But we mainly aim to emphasize that any theory of the power of judgment has to give pride of place to the selfreflexivity in judgment. Let us now briefly introduce how we understand the scope and aims of the paper:

First of all the enterprise does not start with making substantive assumptions about the human being and its relation to the world. The attempt is rather to explore whether there are 
formal preconditions to understanding understanding: whether the self-reflexivity in judgment exhibits a necessary structure, which would make it possible to reconstruct what we would have to presuppose if we are to understand anything at all. The reason behind this is not to place areas of our (self)understanding beyond contestation, it is rather aimed to reconstruct which assumptions and faculties are needed for contestation in the first place. Differentiation presupposes similarity, and discussion presupposes shared standards of understanding (Wittgenstein 1968; Nietzsche 1994). It may be possible that analysis of formal preconditions of the structure of judging will have substantial implications, in the sense that it may lead to conclusions about what has to be thought and what necessarily falls outside of limits of possible understanding. But the aim is not to start with these; and in that sense we understand the endeavor in line with a 'transcendental philosophy of mind' (Makkreel 1984: 311), 'a priori psychology'. (Waxman 2014: 4), or 'transcendental phenomenology' (Beyleveld and Ziche, this volume).

However, second, such a transcendental approach does not see the human being as an entity that is abstracted from its historical, social, and linguistic horizons: any attempt to understand the power of judgment needs to assume that when there is judgment there is a judging subject, and this implies assuming that there is a horizon in which objects of judgment can have significance to this subject. This means that we necessarily think the judging subject in context of historical, social and linguistic horizons - a contextual embedding that is given significance in a 'community of judgment' (Herman 2007). We do not think about judgments as if these were first formed by the subject in isolation and only in secondary instance articulated in language. Although our line of thinking bears similarities to the later hermeneutical tradition, we do not share some of its methodological starting points, especially those in line with Gadamer's claims that judgment inherently fixes our thinking in a problematic way and therefore priority should be placed on tradition (Gadamer 2013). If we appropriate the term 'hermeneutic', we understand it as the self-reflexivity in judgment from the internal perspective of the judging subject - which should not be interpreted as conflicting with but rather in relation to more context directed aspects of judgment. ${ }^{1}$

Third, in a specific sense then, we understand universalism here in a perspectivist way: the challenge lies in reconstructing the universality in the formal structure of the self-reflexivity in judging, whereby it in the first place becomes possible to understand what it implies for the subject to develop and communicate his own perspective on anything at all. That means that it concerns the perspective of each human being and what is presupposed in order for him to understand his own judgments. We do not presuppose here that such a universal theory of judgment can be drafted, we rather want to explore the possibility: it may be ultimately impossible to make judgments about understanding understanding that distinguish between form and content in a way that legitimately claims universal appeal. Perhaps the scope of what we can formally reconstruct is so limited that it is impossible to make universal judgments that have any concrete significance, and that art rather than philosophy is important for understanding ourselves. Perhaps ultimately we would have to recognize the contingency of judgment, and turn 'against theory and toward narrative'. ${ }^{2}$ (Rorty 1989: xvi) One could

\footnotetext{
${ }^{1}$ We owe this point to a very insightful review of the first version of this paper.

${ }^{2} \mathrm{NB}$ : We do in no way claim that philosophical as distinguished from e.g. literary judgments are somehow 'more important' to (self)understanding. Indeed: we will argue below that the capacity for reflexive aesthetic judgment is prerequisite for the possibility of moral judgment. At the same time we hold that aesthetic judgments belong to a different category than moral judgments, and similarly we would uphold a strict distinction between philosophy and literature/poetry - for the sake of the authenticity and autonomy of both forms of reflection and interpretation.
} 
wonder whether such a claim can at all be made without reverting to exactly the theory that is renounced - but even if the position could otherwise be proven valid this would have tremendous consequences: we would lack a basis to make any normative claims whatsoever. This should be resisted up to the point that philosophical (self)reflection unambiguously shows that this is the only rationally justifiable conclusion.

This then is how we understand the context and the stakes of questions regarding the understanding of understanding: as a challenge to reconstruct the universal structure of the self-reflexivity in judgments in general. The methodological approach is in basis characterized by the attempt to distinguish between necessary form and possible content: the former is explored as foundational ground for claims about the power of judgment with universal aspiration, the latter is abstracted from in order to leave open room for differentiation and discussion.

\section{The Structure and Justification of Moral Judgment}

Many of our judgments are 'assertoric' judgments: they assert that something is or is not the case. 'This is a cat', 'the cat is not on the mat' are assertions about things/states of affairs in the world. Now although prudential judgments of the form ' $\mathrm{X}$ is good' - where good is understood in a non-moral way - perhaps at first glance seem to be assertoric judgments, these are quite different. Prudential judgments, unlike assertoric ones, have to be understood as 'reflexive judgments' (Steigleder 1999). Reflexive judgments are specific types of judgments that are irreducibly self-referring: these pertain to the judging subject himself. The reflexive judgment corresponding to the first assertoric example would be 'I believe (think, hold etc.) that this is a cat', where the internal perspective of the subject is irreducible. Prudential judgments are always reflexive judgments: judgments about the non-moral good cannot be understood independent of the internal perspective of the subject. We can understand prudential judgments as articulations of those goals that are part of our desire for happiness, so these are not general judgments of what one should value but rather judgments that, from the perspective of the judging subject, are considered goals that are worth striving for. So when I judge 'wine is [prudentially] good', an irreducible part of my judgment is that I consider wine as good for me. This is not to say that every time an agent effectively makes a judgment about a prudential good he would interpret himself as making a reflexive judgment - in many cases it can be hard for him to imagine the possibility that someone could not share his taste. What we claim rather is that he can only understand this judgment by seeing it as a judgment that pertains to him: it would be contradictory for an agent to understand himself as judging 'wine is good' and at the same deny that the judgment is his. But if there is necessarily a reflexive element in such a prudential judgment, then it presupposes some form of self-reflexivity in understanding one's own prudential judgments - a form of self-reflexivity that is important if we want to relate this kind of judgment to other forms of judgment.

The next question then would be whether starting from such a prudential perspective there are judgments that any subject, from his internal perspective, necessarily has to make ${ }^{3}-$ or as Gewirth formulates it: whether there are 'dialectically necessary judgments' that all agents, to the extent that they claim to understand themselves as agents, ought to be committed to

\footnotetext{
${ }^{3}$ As indicated we especially focus on practical judgment here. For a reconstruction of the theoretical dimension of the Kantian power of judgment or understanding understanding see Longuenesse (1998), Waxman (2014).
} 
(Gewirth 1978: 42-7; 152). From the Kantian viewpoint, in a purely formal sense there are two. First of all, to the extent that I understand the object of my prudential judgment as a good, I must judge it as action-guiding. I must judge it as an end by which I am motivated. That does not mean that when I have an appetite for wine I will immediately open a bottle; perhaps there are other considerations that make me refrain from drinking - e.g. prudential considerations about not wanting to wake up with a headache, moral judgments about drinking and driving etc. But to the extent that I judge that wine is a good, I must understand it as an end. Second, judging something as prudentially good implies transferring the evaluation to the "means to take to it in certain circumstances' (Kerstein 2013: 46). When I consider opening the bottle as the necessary means to drinking wine, then to the extent that I judge drinking wine as good I must also judge opening the bottle as good - at pains of self-contradiction.

Now Gewirth's argument goes further than this in that he ultimately formally universalizes substantive content, whereby he derives the principle of morality (i.e.: the Principle of Generic Consistency, or PGC) from the prudential judgment by showing that a commitment to certain convictions necessarily implies a commitment to certain other convictions as well. The argument comes in three stages. First: to the extent that I understand myself as an agent who is motivated to achieve any purpose whatsoever, I have to evaluate specific 'generic goods' as generic conditions for my agency (Gewirth 1978: 52). Independently of the purposes I am motivated to achieve, it is dialectically necessary for me to value freedom and well-being as conditions because these are the necessary conditions for all possible goal-achievement. If I understand myself as a practical being, that is: if I understand myself to have prudential commitments at all, then I ought to judge freedom and well-being as instrumentallycategorically good - as goods that I value 'categorically as a means' (Beyleveld 2013). Under the condition that I am vulnerable because these goods are endangered and the possession of these goods depends on the conduct of others (Steigleder 1999), this implies, second, that I am rationally committed to judge freedom and well-being as prudential goods that I want others not to infringe upon. I have to want that others to not prevent me in having these prudential goods to the extent that I consider these as necessary means to my ends. In other words, I consider myself to have 'claim rights' (Hohfeld 1964) against others. Now, in a community of judgment, which is the historical, socio-linguistic horizon in which the question of judgment arises in the first place, my instrumentally-categorical commitment to freedom and well-being is other-directed. That means that I have to understand my claim to freedom and well-being in terms of a right that is strictly correlated with a duty of others. This is not (yet) a moral, but a conceptual claim: to the extent that I understand myself as making a claim to freedom and well-being, I (logically) have to hold that others prudentially should respect me in that claim. This is not to say that already at this stage of the argument we can identify concrete others as duty-bearers. It is rather that I need to want that others in general do not interfere with my generic goods. However, the only way in which I can consistently judge that I have a claim right to freedom and well-being, is by understanding my generic features of agency, third, as the basis of that claim right. According to Gewirth I cannot assume (at pains of self-contradiction) that I have a claim right to freedom and well-being on basis of being named Wordsworth Donisthorpe, belonging to one religion rather than another: I can only adduce features that pertain necessarily to my agency as the sufficient reason for ascribing a prudential right to freedom and well-being to me (Gewirth 2000: 493). But this implies endorsing 'I have a claim right to freedom and well-being only because I am an agent', which means that the judging subject ought to endorse a conceptual connection between his being an agent and his claim rights to the generic conditions for agency. But here we do no longer understand rights merely in a prudential sense: now I ought to acknowledge that every 
agent has claim rights to freedom and well-being, which means that 'I ought to act in accord with the generic rights of my recipients as well as myself' is an objective and universal standard for action - the PGC, or moral judgment.

It has been argued elsewhere that moral judgments must be understood to include the following structural features (Düwell 2014: 23-50). Moral judgments must first have a prescriptive dimension: they make claims about what we ought (not) to do. Second, these lay claim to universal validity: moral judgments must be assumed to have normativity for all (prospective) agents. Third, moral judgments should be considered as overriding: their moral character makes them considerations that are understood to trump others. This means that the power of judgment claims a special status for moral judgments vis-à-vis prudential ones.

Tying this together, we claim the following: understanding a judgment as mine, which is necessary to understanding prudential judgments at all, presupposes self-reflexivity in judgment. A further level of self-reflexivity is involved insofar as the step from a prudential judgment to a moral judgment introduces a distinction between necessary and contingent goods in saying that freedom and well-being ought to be judged as goods that I value as necessary means. In the social context this amounts to understanding my commitment to freedom and well-being as other-directed, a claim that I can only justify to myself on basis of the features that pertain to me as an agent - and not to my contingent features. This makes that I ought to recognize that I have a commitment also to respect other agents' claim rights to the generic conditions of agency (at pains of self-contradiction). Therewith, my commitment to moral judgment is justified because it follows dialectically necessarily follows from understanding any prudential judgment (as mine). And thus I am committed to the idea of a universal overriding prescription, at pains of self-contradiction. ${ }^{4}$

Such a transcendental justification has received much criticism, where most of the critique questions the justificatory potential in convincing the moral skeptic. E.g. David Enoch says that it is not sufficient to show that certain capacities are constitutive for agency: it is also necessary to show that we have reason to play the agential game - 'that we have reasons to be agents rather than shmagents' (Enoch 2006: 186). To an extent this charge seems misguided, at least when it is aimed at the Gewirthian type of transcendental justification: my commitment to my own prudential judgments does gives me a reason to play the agential game. It does not mean that I will of course: perhaps the egoist does not consider the pain of self-contradiction as sufficiently painful. But that is not an argument against the justification - it seems rather to express pessimism with regards to the human being's willingness to listen to reason at all. However, if the justification holds: if it holds that subscribing to prudential judgments commits me to moral judgments, it does not as yet explain how we can understand the normativity of seeing ourselves as practical beings. One could think of Laozi's wú wéi: the doctrine of nonaction, where (in an oversimplified version) the Daoist sage aims to transcend the "me and mine" by abstaining from committing himself to prudential ends altogether (Laozi 1954). Or perhaps of the "characters" (read: numbers) in Zamyatin's We, who are portrayed as borg-like

\footnotetext{
${ }^{4}$ Steigleder has demonstrated that Kant's doctrine of imperatives can be interpreted in a similar vein (2002: 2358). In this interpretation we can see hypothetical imperatives as technical and prudential commitments of an agent. A rational agent would be an agent that is able to form 'maxims', that is: to bring his actions under rules, and to evaluate those maxims. Those maxims are evaluated in technical, prudential and moral perspectives according to the three forms of imperatives that Kant distinguishes. In that sense not only the categorical imperative but also the two forms of hypothetical imperatives have practical necessity for the agent; the difference is only that the hypothetical imperatives are conditionally necessary while the categorical imperative is obligatory under all circumstances.
} 
creatures (ultimately) capable of nothing other than assertoric judgment (Zamyatin 1972). Here, we suggest, lies rather the source of doubt from which criticisms like that of the moral skeptic originate: the question of entering the space of reasons is ultimately nothing other than the question why I should care about understanding myself. ${ }^{5}$ It may be that it is ultimately only possible to answer this question by reverting to moral realism, but it would be important to explore alternatives - even if moral realism could explain the 'why', it would have difficulty explaining how the transition between proof of morality from the "outside" (independent of our beliefs) and the understanding of the normativity of practical self-understanding from the internal perspective of the agent could be accounted for. We explore one alternative here by focusing on the role of aesthetic reflexivity.

\section{The Self-Reflexivity of the Aesthetic Judgment}

We have said that practical judgments, because of their self-reflexive dimension, cannot be assertoric judgments: these cannot be understood as if independent of the internal perspective of the subject. But practical judgments are not the only judgments that bear an indissoluble relation to self-reflexivity, to self-understanding, also aesthetic judgments do.

There are situations wherein we relate to the world without aiming to know what we experience, without a desire to consume it, without even the will for it to exist. Often we relate to the world without any interest whatsoever. But a disinterested state of mind is not necessarily equivalent to that of a zombie: it does not imply that we are unaware of our surroundings, nor that these do not mean anything to us - there are situations wherein human beings reflect upon the world without any particular interest (Kant 2000: 5:211). At hand examples are contemplating the vastness of the ocean or being carried away by a musical performance, but such disinterested judging is much more common than we tend to think - it can vary from watching the leaves blow in the park on a windy afternoon, experiencing a moment of intimacy with a person we care about, to being struck by the appearance of an everyday object that transcends its functionality. ${ }^{6}$ Kant calls such experiences aesthetic, and the appropriate judgment reflective. The disinterestedness characteristic to the reflective judgment of aesthetic experience gives it a peculiar status and structure: 'Rather than being directed or necessitated from without, reflective judgment can be considered self-orienting' (Makkreel 2015: 60). That is, there are no clear and distinct concepts or ideas that we apply, and which thus guide, the way that we as subjects relate to the object in experience: in reflective judgment we are rather in the process of orienting ourselves in the way we subjectively respond to the world of experience. And that implies that there is an irreducibly reflexive dimension to the aesthetic reflective judgment. ${ }^{7}$ Now of course there are different kinds of ways in which we can experience our surroundings in such reflexivity (Seel 1991; Düwell 2000): as beautiful or ugly,

\footnotetext{
${ }^{5}$ One of the reviewers commented that we had not explained why reflexive judgment is dialectical judgment: why reflexive judgment can and should be interpreted as including necessary commitments from the internal viewpoint of the judging subject. To an extent this can be interpreted as a different formulation of this point: how we can understand why a being with the capacity to make reflexive judgments should step into the game of making inferences conditioned by rules such as the principle of non-contradiction at all. In that light the following section about aesthetic judgment could be seen as an attempt to flesh out the peculiar necessity of dialectical necessity - or metaphorically speaking: the painfulness of the pain of self-contradiction.

6 The latter example being made immortal by Heidegger's reflections on a pair of farmers' shoes. (Heidegger 1960)

${ }^{7}$ And indeed: possibly in reflective judgment in general. Cf. also Makkreel 2015: 165-66
} 
harmonious or alienating, meaningfully structured or chaotic. Walking through the abandoned city center of Utrecht on a dreary Sunday afternoon can be very joyful for you and depressing for me, and the similar holds for the subject internally. I can judge the same recording of Pergolesi's Stabat Mater as deeply melancholic the one day, and annoyingly hopeful the nextand in the same line sunny weather can sometimes uplift my spirits, but at another time make me all the more blue because it does not correspond to my feelings. What these examples indicate is that the aesthetic judgment does not directly or not primarily concern the object of experience: it judges rather the way it is experienced. Of course it is not just a projection on my inner feelings on the external world, it is the surroundings that trigger this aesthetic experience: when I judge 'this [warm and sunny] weather is absolutely depressing' my judgment is "about" the weather but only in the sense that I judge the quality my surroundings have for me. In metaphorical terms we could say that the aesthetic judgment functions "as if" it judges assertorically or prudentially: as if it makes a judgment that is similar to ' $\mathrm{X}$ is green' or ' $\mathrm{X}$ is good', but at the same time it does neither - it neither judges that something is (not) the case, nor can it be analyzed through recourse to my will (Beyleveld and Ziche this volume; Düring and Düwell forthcoming).

In more technical terms Kant says that the power of judgment is exercised here in a way that is the result of a 'free play' (Kant 2000: 5:217) of our cognitive capacities. In aesthetic reflection we judge the world as aesthetically valuable (beautiful or sublime), where such an aesthetic experience is a goal in itself. That we are able to exercise our cognitive capacities in such a free fashion has animating effects on us, and triggers our understanding of the world and ourselves in different ways - but these effects are only possible because of the freedom that aesthetic experience makes accessible to us. In this way aesthetic experience allows us to develop a peculiar self-reflexive space or playroom in which we have a certain distance to the views we have on the world, and in this quality it is relevant for our capacity to judge as such. But it is not a form of pure thinking; the aesthetic judgment is not empty but always about specific objects. Aesthetic reflexivity and judgment implies a specific distance, but only a distance from the immediate involvement in my understanding of the world and not from my surroundings. This makes possible precisely reflecting upon $m y$ view, as the particular finite agent that I am. The self-reflexivity of the aesthetic reflection creates a distance from my theoretical and practical judgments in the sense that it is neither concerned with the objectivity of our knowledge of the world nor with the desirability or moral quality of a goal of action. We rather experience ourselves as creative beings that can play with our capacity to judge, and can exercise this capacity in a free fashion - that can explore the phenomenology of being a judging subject for no other reason than exploration itself. And not merely in quality of the judging subject in the formal sense: the aesthetic distance from my desires and theoretical knowledge allows me to reflect upon who $I$ am as the particular judging subject that reflects upon itself in relation to his experience of the world. And especially also who I am in relation to other people: there is a social dimension inherent to aesthetic reflection. Kant indeed goes so far to say that the capacity for aesthetic experience and judgment - taste - should be understood as the 'sensus communis': the 'faculty for judging that in its reflection takes account (a priori) of everyone else's way of representing in thought' (Kant 2000: 5:293). That obviously does not mean that aesthetic reflection is itself moral: it means rather that in the aesthetic distance from concepts, desires, our particular views on the world, lies the possibility for sensitivity towards other people's perspectives, feelings etc. And crucially: this is made possible by the imagination. The reason why I can adopt a distance from my judgments in a way that precludes a distance from the world is because the imagination is active and creative- 
free. Imagination makes it possible for us to judge the weather as if it were depressing, a landscape as if it were created so that I can bear witness, a musical piece as if it expressed my emotions, a blue flower as if it represents romantic love. The imagination makes possible our as-if judgments that are not purely cognitive but playfully appear to establish a relation to the world.

We would suggest that the distance in aesthetic reflection is essential for human beings to develop their own perspective on the world and themselves as judging subjects in that world. Aesthetic reflection, the conscious perspective on the world without any particular interest, draws human beings into the 'game of understanding understanding' and enables them to develop a reflexive space to their own perception of the world and its interpretation in the community of judgment. If this holds, then the capacity for aesthetic reflection is an important element of our practical self-understanding: aesthetic reflection allows human beings to develop a relation to their judgments, which allows them to understand themselves as beings to whom their practical commitments have significance.

\section{Mixed Moral Judgments in Complex Circumstances}

If we have been right in arguing that prudential, moral, and aesthetic judgments are all reflexive judgments that presuppose a self-reflexive dimension, then all three forms play a crucial role in how we orient ourselves in the world. If we would not be able to adopt a reflexive space to our judgments, then we would not be able to systematize these: we would not be able to relate different judgments to each other, establish hierarchies of relevance and normativity - our varying judgments would merely constitute an aggregate of independent and unrelated judgments. The case of 'mixed' judgments is in this regard particularly challenging since these presuppose that we are capable of linking judgments of different kinds to each other in a non-arbitrary way. The power of judgment in its self-reflexive employment is prerequisite to developing a unified whole out of our singular judgments: to developing a perspective that is our own. The question is which functions the three kinds of judgment respectively play in creating such 'unity in the manifold' (Kant 1998: A97-8). We will here explore three conceptual possibilities, they do not exclude each other and doubtless there are more.

A first possibility would be to think that aesthetic self-reflexivity is preparatory vis-à-vis prudential and moral judgment. As said before, if we would not have the creative potential of the imagination, it is questionable how we could enter the 'community of judgment'. We would not be able to develop a prudential perspective of our own. The incapacity to do so would make it impossible for us to transcend immediate judgments and engage in prudential or moral reasoning in the first place. Imagine (pun intended) I would only be able to develop judgments that articulate my direct preferences, e.g. 'I like wine'. How could I make the step to relate this preference to other commitments I may have? How would I start to form hierarchies of judgments and start to deliberate about the relationship between my preferences and wishes? And if I would not be able to develop such an ordered and structured relationship between my judgments, how could I enter the space of moral deliberation? There must be a self-reflexive step to allow me to get engaged in prudential and moral reasoning at all. Of course, a disturbing experience can occur that makes me correct my prior preferences; e.g. Liebfrauenmilch could make me doubt my previous 
assumption that in general I like wine, and it may be that I experience cruel behavior by other people that makes me start reflecting on whether it is morally acceptable to behave like this. In that sense is it not necessarily an aesthetic experience that initiates the self-reflexivity in judgment. But the possibility of the distance of the aesthetic experience and the possibility of the free play of our cognitive capacities seems to be the entrance par excellence for entering this space of practical deliberation.

A second possibility would be that aesthetic self-reflexivity is an integral part of moral judgment. In forming moral judgments we need some form of distance from our direct involvements in our various life projects; we need the possibility to discover what kind of moral actions are possible and accessible for us. To understand myself e.g. as morally obliged to refrain from using a Volkswagen diesel for reasons of sustainability presupposes capacities that have links to (aesthetic) imagination. I have a) to imagine myself as someone who does not identify with those commitments, that I am able b) to imagine myself in someone else's shoes, that I c) have the imaginative powers necessary to anticipate the consequences climate change may have for people in distant (developing) countries and for future generations, and d) that all these reasons make that I develop an understanding of the role of my own actions in light of these possibilities. Such an imaginative step will not replace moral deliberation nor the justification of moral judgment. But it is necessary for a moral judgment that can be both justifiable and concrete. It is obviously clear that not all of the possible imaginative steps are dependent on aesthetic reflection: I can form images of future events by reading novels, but also by methods of technology, probability calculation and risk assessment. But we can wonder how limited our scope of moral reasons would be without the possibility of transcending our own experiences via active imagination.

A third possibility would be that aesthetic self-reflexivity is an integral part, not just of the moral, but also of the prudential judgment. If we wonder how we should understand setting something as an end, then we could again wonder what role the imagination plays here. Especially if longer-term ends (future ways of living), ends that would imply a change of direction of my life (living as a farmer in Northern Italy), or complex ends (working on one's anger management) are concerned, we have to include imagination in our judgments. In both longer-term and complex cases (at least) we judge an underdetermined image as if it were an end from which we could unambiguously derive the means. If I would not have the capacity to imagine those ends, I could hardly grasp what it would mean for me that it is $m y$ end. And we could very well ask whether not the imagination in its free employment plays an important role here. The aesthetic imagination enables us to simply play with the possibility of such an end without being directly committed to it as an end that we actually set. This capacity enables us on the one hand to imagine an end as a possible end, and on the other hand to distance ourselves from it because it does not imply a direct commitment. This makes it possible to engage in prudential reasoning because we have an initial understanding of the relevance of this end but are still in need of integrating this end in the broader perspective of a life we want to live.

These considerations show that aesthetic judgment can have a variety of functions in our practical self-understanding in general. It is particularly important when we think about the mixed judgments that are relevant in practical deliberation, especially for deliberation under complex circumstances. Let us return to the example of the long-term responsibilities with which we started at the beginning of this paper. Longtermism presupposes that we form mixed 
judgments that bring together more general moral reasons with regard to the obligations human beings may have, a variety of facts about the natural world, knowledge about climate prognoses, unpredictable future consequences, understanding of the way political institutions regulate human action, how people tend to behave etc., and to relate these aspects to how we understand ourselves as agents. Simply possessing ecological knowledge about climate change is insufficient because such knowledge only can be significant for our practical judgment if we are able to bring all those considerations together in a mixed judgment. It is not a question of how such a judgment can be inductively or deductively developed. Of course there are all kinds of probabilities, priority rules etc. that are important in the development of these judgments. But we cannot simply deduce factual, prudential, and moral judgments from each other. Bringing them together in one judgment necessarily involves some elements of imagination. That does not mean that we should ignore climate scientists and rather ask Steven Spielberg to guide us in thinking the future. It means that it is difficult to see how the unification of those perspectives would be possible if we would not be able to bring those judgments together in an imaginative process, and have the possibility to develop alternative perspectives on the future and our possible role in bringing this future about in aesthetic judgment. This would also be crucial in developing shared perspectives that allow space for action on the collective level (Ferrara 1998; Innerarity 2012).

It is of course important to emphasize that aesthetic exploration of our space of possibilities is not meant to replace moral and political deliberation, on the contrary. But we should see it as a task of moral deliberation to include these imaginative dimensions. It is also not meant as an instrumentalization of aesthetic experience for moral purposes. Aesthetic experience can only be relevant for practical deliberation due to the free play of the cognitive capacities; if we would try to use art for moral purposes we would lose the capacity of self-reflexive judgment - art would be propaganda rather. Of course, all these considerations would have a variety of normative consequences, of which we will mention only two, surely there are more:

In the first place it would have consequences for how we understand philosophy of education. If aesthetic reflection does have the role we claimed above, then being allowed the possibility for free play is crucial to developing one's own perspective that allows for moral self-reflexivity. And this would imply that an education system that focuses on mere knowledge transferal at the expense of the cultivation of selfinterpretation in light of perspectives that are more closely associated with the humanities would constitute a problem related to directly to the possibility of a reflected forms of practical self-understanding. This does not mean that children should be educated with the aim to "teach" them "important" values. It is rather aimed to allow them the possibility of reflecting on their own values, their own desires, and what they know of the world in an autonomous way: to play with judging their judgments, and therewith learning for themselves how they can orient themselves in the world.

One could also wonder whether a government that understands the arts as superfluous in times of necessary economic reforms is indeed as innocent as is often depicted. Although fundamentally all objects of experience can potentially be objects of aesthetic reflection, the arts have an exemplary role therein. If what we have suggested in the above has any plausibility, then cutting down on the arts is not a morally neutral choice. It is not directly immoral, surely, but in a more indirect way it impedes the possibilities for subjects to develop their self-reflexive potential - their capacity for moral judgment. 


\section{Looking Forward}

We are aware that in this short paper we could not map out an encompassing approach to the power of judgment. At least we hope that we have made plausible why the topic is important. To be able to develop accounts of a theory of judgment that clarifies how we can judge complex questions of action, we need to see the power of judgment as conditional on understanding as such. To systematically reconstruct the working of this capacity presupposes that we understand the relationship between different forms of judgments and the access to self-reflexive judgment. To the extent that aesthetic judgment becomes a possible prerequisite to entering the space of reasons, it is even possible that the capacity to form aesthetic judgments fulfills an indispensable or at least relevant function in developing a perspective of our own, which is a precondition for moral judgment. Our paper has investigated a variety of conceptual links that are already present in the Kantian system but that are only to a limited degree present in the contemporary discourse. We would stress that it is important that this is changed: we should invest in understanding the capacity of judgment because it is the key to developing a more reflexive form of practical self-understanding.

Acknowledgments We owe our gratitude to Annemarie Kalis and Niels van Miltenburg for their comments on the first draft of the paper.

Open Access This article is distributed under the terms of the Creative Commons Attribution 4.0 International License (http://creativecommons.org/licenses/by/4.0/), which permits unrestricted use, distribution, and reproduction in any medium, provided you give appropriate credit to the original author(s) and the source, provide a link to the Creative Commons license, and indicate if changes were made.

\section{References}

Beyleveld D (2013) Gewirth v. Korsgaard on universalization. J Moral Philos. http://dro.dur.ac.uk/10855/1/ 10855.pdf, Accessed 20 Feb 2015

Beyleveld D, Ziche P (this volume) Towards a Kantian phenomenology of hope

Düring D, Düwell M (forthcoming) Hope, agency, and aesthetic sensibility. In: Ethical rationalism and the law. Hart, Oxford

Düwell M (2000) Ästhetische erfahrung und moral. Alber Thesen, Freiburg

Düwell M (2014) Human dignity: concepts, discussions and philosophical perspectives. In: Cambridge handbook on human dignity. Cambridge University Press, 23-50

Enoch D (2006) Agency Shmagency: why normativity won't come from what is constitutive of action. Philos Rev 115(2):169-198

Ferrara A (1998) Reflective authenticity: rethinking the project of modernity. Routledge, London

Gadamer G (2013) Truth and method. Bloomsbury, London

Gewirth A (1978) Reason and morality. University of Chicago Press

Gewirth A (2000) The justificatory argument for human rights. In: Ethics: classical Western texts in feminist and multicultural perspectives. Oxford University Press, 489-494

Heidegger M (1960) Ursprung des kunstwerks. Reclam, Stuttgart

Herman B (2007) Moral literacy. Harvard University Press

Hohfeld WN (1964) Fundamental legal conceptions as applied in judicial reasoning. Yale University Press

Innerarity D (2012) The future and its enemies: in defense of political hope. Stanford University Press

Kant I (1998) Critique of pure reason. Cambridge University Press

Kant I (2000) Critique of the power of judgment. Cambridge University Press

Kerstein S (2013) Kant's search for the supreme principle of morality. Cambridge University Press

Laozi (1954) Tao te ching: the book of the way and its virtue. Murray, London

Longuenesse B (1998) Kant and the capacity to judge. Princeton University Press

Makkreel R (1984) Imagination and temporality in Kant's theory of the sublime. J Aesthet Art Crit 42(3):303-315 
Makkreel R (2015) Orientation and judgment in hermeneutics. Chicago University Press

Nietzsche F (1994) Homer on competition. In: Ansell-Pearson K (ed) On the genealogy of morals. Cambridge University Press

Rorty R (1989) Contingency, irony, solidarity. Cambridge University Press

Seel M (1991) Eine ästhetik der natur. Suhrkamp, Frankfurt a/M

Steigleder K (1999) Grundlegung der normativen ethik. Der Ansatz von Gewirth. Alber, Freiburg/München

Steigleder K (2003) Kants moralphilosophie; die selbstbezüglichkeit Reiner praktischer vernunft. JB Metzler, Stuttgart

Waxman W (2014) Kant's anatomy of the intelligent mind. Oxford University Press

Wittgenstein L (1968) Philosophical investigations. Blackwell, Oxford

Zamyatin Y (1972) We. Avon, New York 